\title{
Development and Incorporation of Nanoemulsions in Food
}

\author{
Antonio de J. Cenobio-Galindo ${ }^{a}$, Rafael G. Campos-Montiel ${ }^{a^{*}}$, Rubén \\ Jiménez-Alvarado ${ }^{\mathrm{a}}$, IsaAC Almaraz-Buendía ${ }^{\mathrm{a}}$, Gabriela Medina-PÉrez ${ }^{\mathrm{b}}$, And \\ FABiÁn FERnÁNDEZ-LUQUEÑO ${ }^{\mathrm{c}}$

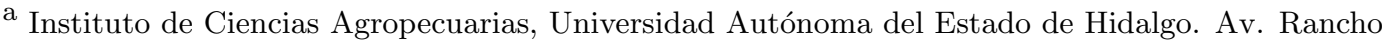 \\ Universitario s/n Km. 1. Tulancingo, Hidalgo, C.P. 43600, México \\ b DCTS, Cinvestav-Zacatengo, Ciudad de México, CP 07360, México \\ ${ }^{\mathrm{c}}$ Sustainability of Natural Resources and Energy Program, Cinvestav-Saltillo, Coahuila, México \\ ${ }^{*}$ Corresponding author \\ ragcamposm@gmail.com \\ TEL: $+(52) 7717172000$ EXT. 2422
}

Received: 1 August 2018; Published online: 18 October 2019

\begin{abstract}
Currently, nanoencapsulation of bioactive compounds is promising, and is one of the methods that has been proven very effective. The development of food-grade nanoemulsions is in a state of constant innovation due to the interesting features that this method of encapsulation has, such as small droplet size, kinetic stability and appearance. With this technology, it is possible to control some food properties, such as texture, taste and stability. In this article, we present a review of the most commonly used methods in the creation of nanoemulsions, the recent developments of these dispersions, the relevant applications of nanoemulsions in food matrices, the most commonly used food-grade materials and the functionality of nanoemulsions, which are designed primarily to encapsulate compounds with biological activity. Nanoemulsions have been shown to be effective in preventing degradation and improving the bioavailability of bioactive compounds, such as oil-soluble vitamins, antimicrobials, flavours and antioxidants. At the end of this article, facts of interest about acceptance issues and nanotechnology regulatory policies in the food industry are presented.
\end{abstract}

Keywords: Shelf life; Antimicrobial; Essential oils; Encapsulation

\section{Introduction}

The word "nano" is used in all areas of science and technologythat deal with the characterization, manufacture and operation of structures, devices or materials with sizes on the nanometre scale (Duncan, 2011; Pradhan et al., 2015). All foods developed and consumed since ancient times co contain natural nanomaterials because plant and animal products contain multiple nanostructures; and based on their size, foods can be classified within these categories (Magnuson, Jonaitis, \& Card, 2011).

Copyright (C)2019 ISEKI-Food Association (IFA)
The food industry has made important advances with the application of nanotechnologies, such as nanoliposomes, nanoemulsions, nanofibres, and nanocapsules, to obtain fresh and better-tasting foods (Raj, Ragavi, Rubila, Tirouthchelvamae, \& Ranganathan, 2013). Nanoemulsions are colloidal systems of particular interest because they can be made from food-grade ingredients and use processes in the food industry, such as blending, thermal treatment and homogenization (Rao \& McClements, 2011). The food industry uses these science and technology principles of emulsions to create and transform a wide variety of 
foods and beverages (McClements, 2010).

One of the main advantages of using nanoemulsions is that the food manufacturer can improve some properties, such as appearance, texture and/or taste, through careful selection of the ingredients and the processes used to make them (McClements, 2015). Another advantage of nanoemulsion use is that emulsions can have better stability against the coalescence of droplets (McClements \& Rao, 2011). Additionally, droplets are transparent when dispersed, so they are suitable for addition to food without modifying the appearance characteristics (Mason, Wilking, Meleson, Chang, \& Graves, 2006); the appearance of a colloidal dispersion tends to become translucent or transparent when the particle radius falls below approximately $100 \mathrm{~nm}$. These dispersions can increase the bioavailability of certain nanoemulsified compounds (Acosta, 2009). Recent research on nanoemulsions has focused on their manufacture, characterization and use as release systems (McClements, 2012). Therefore, the present work aims to review the application trends of nanoemulsions in food, the materials used, and the risks and regulations to consider in the use of nanotechnology.

\section{Nanoemulsions}

According to McClements (2012), a nanoemulsion is a thermodynamically unstable colloidal dispersion consisting of two immiscible phases (nanoemulsions have better stability in particle aggregation and gravitation separation due to their small droplet sizes compared to that of macroemulsions). One of the phases contains dispersed particles and small droplets in the other (normally $\mathrm{r}<100 \mathrm{~nm}$ ); this resultant dispersion has a translucent appearance. These nanoemulsions may be emulsions of oil-in-water $(\mathrm{O} / \mathrm{W})$ or water-in-oil $(\mathrm{W} / \mathrm{O})$.

The proportions of water and oil in a nanoemulsion must be carefully designedas a large variety of components are often incorporated in the aqueous phase (such as proteins and polysaccharides, among others) (McClements \& Rao, 2011). Polysaccharides (pectin, gums, and others) are used to stabilize these systems because of their high viscosity (Choi, Kim, Cho, Hwang, \& Kim,
2011). In the creation of nanoemulsions, several oils (such as essential oils), acylglycerols and free fatty acids are used (Shah, Bhalodia, \& Shelat, 2010). Lipophilic active ingredients, such as vitamin E, carotenoids, and curcumin, are also used. The addition of these active components totally changes the physicochemical properties and activity of the nanoemulsions (Jin et al., 2016; Shakeel et al., 2010). Commercially, nanoemulsions have been designed to encapsulate components with a lipophilic nature because these components may not be well dispersed in aqueous media. However, it is possible to manufacture W/O-type nanoemulsions with rheological behaviour such as colour, appearance, texture and stability (Jafari, Assadpoor, He, \& Bhandari, 2008) that produce desirable characteristics in food applications. Emulsions are systems that are not in equilibrium, and they tend to separate into their constituent phases (Gutierrez et al., 2008). For a nanoemulsion, the free energy of the emulsion is greater than the free energy of the separate phases (oil and water), which means that a nanoemulsion is thermodynamically unstable. A nanoemulsion can be made kinetically stable (metastable) by ensuring that there is a sufficiently large energy barrier between the two states. The height of the energy barrier is mainly determined by physicochemical interactions that prevent the droplets from coming into close proximity with each other, such as repulsive hydrodynamic and colloidal (e.g., steric and electrostatic) interactions operating between droplets (McClements, 2012). Thermodynamic instability occurs through certain mechanisms, such as sedimentation, coalescence, flocculation and Ostwald ripening (Gharibzahedi, Mousavi, Hamedi, \& Ghasemlou, 2012). According to Solans, Izquierdo, Nolla, Azemar, and Garcia-Celma (2005), nanoemulsions can possess high kinetic stability and persist for many years. The stability depends on the preparation method, which affects properties, such as the droplet size. The characteristics of a nanoemulsion will be good if the preparation method uses a high shear or high energy accumulation in the system (Gutierrez et al., 2008). These dispersions exhibit better stability against separation than macroemulsions because of their relatively small droplet size and the effects of Brownian mo- 
tion, which dominates gravitational forces (McClements, 2015). In addition, food-grade nanoemulsions are designed to increase the bioactivity of some compounds that are poorly absorbed (Qian \& McClements, 2011).

One of the most frequent instabilities in nanoemulsions is Ostwald ripening, or molecular diffusion (Gupta, Eral, Hatton, \& Doyle, 2016; Tadros, Izquierdo, Esquena, \& Solans, 2004). This phenomenon occurs when a large droplet increases its size, incorporating a smaller droplet by molecular diffusion (Ahmed, Li, McClements, \& Xiao, 2012). According to Tadros et al. (2004), the high energy required for the formation of nanoemulsions can be understood from the pressure difference between the inside and the outside of a large drop that will divide into smaller drops; the drop must be strongly deformed, which can be shown when a spherical drop deforms into an ellipsoid. The force necessary to deform the drop is greater when the drop is smaller since the energy is generally transmitted by the surrounding liquid through agitation; therefore, more energy is needed to produce smaller drops. The dispersed phase can be controlled through osmotic pressure. In dilute volume fractions, the droplets are spherical, while in high fractions, the surfaces of the droplets are strongly repelled by the surfaces of the neighbouring droplets. This can cause the droplets to deform and become non-spherical. An appropriate surfactant can inhibit the droplets from recombining through interfacial coalescence, making the nanoemulsions stable (Graves, Meleson, Wilking, Lin, \& Mason, 2005). This is due to the difference in the ratio of the curvature of the drops. In addition, this process can be observed in terms of a reduction in the free energy of the system via the destruction of the interfacial zone (Taylor, 1998). With a properly selected emulsifier, Ostwald ripening can be effectively controlled (Kabalnov \& Shchukin, 1992).

\subsection{Methods used to form nanoemulsions}

Understanding the formation of nanoemulsions is essential to create a small droplet size; these dispersions are representatively developed in a two- step procedure in which a macroemulsion is developed and then transformed into nanodroplets (Gupta et al., 2016). Nanoemulsions are created using a series of specific methods, and they can be grouped based on the energy input, i.e., low energy and high energy. Optimal droplets are achieved by these methods, and methods are based on the materials designed for droplet preparation (Jin et al., 2016).

\section{Low-energy methods}

In these methods, a nanoemulsion is obtained when there is a phase inversion in the system due to variations in the conditions or concentrations of the emulsion and a state of low interfacial tension is reached (Gupta et al., 2016). Spontaneous emulsification, phase inversion composition and phase inversion temperature methods are some of the commonly used low-energy methods (Jin et al., 2016).

\section{Method of spontaneous emulsification}

In this method, a nanoemulsion is obtained when organic and aqueous phases are mixed (Anton \& Vandamme, 2009; Miller, 1988). The elaborate procedure can be performed in different ways: the composition between the phases can be modified; the ambient conditions can be altered (temperature or $\mathrm{pH}$ ); or the process conditions can also be altered (e.g., addition order). For example, a hydrophobic oil, a hydrophilic emulsifier, and an organic solvent could be incorporated into water (Anton \& Vandamme, 2009). In addition, water can be incorporated into an organic phase containing an emulsifier and oil (Sonneville-Aubrun et al., 2009). Fine droplets are obtained by altering the composition of the phases and the process characteristics. There are currently no reports in which polysaccharides or proteins have been employed as emulsifiers in this process, which may be due to physicochemical limitations (McClements \& Rao, 2011). Surh, Decker, and McClements (2017) produced nanoemulsions by means of spontaneous emulsification when they encapsulated lutein and obtained nanoemulsions that were stable against the aggregation of drops when the nanoemulsions were stored at room temperature for up to 1 month; 
however, some colour fading occurred due to the degradation of lutein.

\section{Phase Inversion Composition (PIC)}

The PIC method optimizes the curvature of emulsifiers by changing the configuration at a certain temperature. The phase change is driven by the Gibbs free energy of the system and results in a spontaneous inversion of the emulsifiers. The PIC method is used to obtain an $\mathrm{O} / \mathrm{W}$ emulsion by aqueous phase dilution in $\mathrm{W} / \mathrm{O}$ emulsions (Jin et al., 2016; Roger \& Cabane, 2012; SonnevilleAubrun et al., 2009). Another process used to prepare nanoemulsions by this method is to alter the electrical charge (modifying the $\mathrm{pH}$ ) of the emulsion (McClements \& Rao, 2011). Pagan, Berdejo, Espina, Garcia-Gonzalo, and Pagan (2018) prepared nanoemulsions incorporating citral, using the PIC method to evaluate their antimicrobial activity; nanoemulsions were prepared from an oil phase mixture by slowly adding an aqueous phase during gentle magnetic stirring and then increasing the amounts of water added to the system with continuous agitation. The amount of water added to a $\mathrm{W} / \mathrm{O}$ emulsion was progressively increased until a phase inversion occurred, and an oil-in-water emulsion was formed. The results of the study showed that the citral nanoemulsion was more effective than the freeform citral. At the same time, researchers applied a heat treatment and observed that there was an antimicrobial synergistic effect.

\section{Phase Inversion Temperature (PIT)}

The PIT method is based on modifications in the relative solubility of non-ionic emulsifiers with respect to certain temperature changes (Gutierrez et al., 2008). Nanoemulsions are formed using the PIT method via modifications in the structure of non-ionic emulsifiers when the temperature in the system is varied. At low temperatures, the head group of a non-ionic emulsifier is highly moistened and is more soluble in the aqueous phase. Conversely, as the temperature increases, the head group is dehydrated, and the solubility of the emulsifier in this phase decreases (Anton, Gayet, Benoit, \& Saulnier, 2007; McClements \& Rao, 2011). Chuesiang, Siripa- trawan, Sanguandeekul, McLandsborough, and McClements (2018) formulated nanoemulsions of cinnamon oil by heating a mixture of cinnamon oil, a non-ionic surfactant and water above the PIT of the system and then quickly quenched this mixture with continuous agitation, which led to the spontaneous generation of small drops of oil. They formed nanoemulsions with a $101 \mathrm{~nm}$ drop diameter and reported that their nanoemulsions were stable for at least 31 days when stored at $4^{\circ} \mathrm{C}$ or $25^{\circ} \mathrm{C}$.

\section{High-energy methods}

High-energy methods are made using various types of mechanical equipment, such as ultrasonic homogenizers, high-pressure homogenizers, or microfluidizers, that generate enough levels of intensive energy to rupture oil and water, producing small droplets. The energy inputs regulate the properties of the dispersions and prevent droplet rupture and coalescence (Jin et al., 2016).

\section{High-pressure homogenization}

High-pressure homogenization subjects an emulsion to high pressures and then passes it through a controlled valve. High pressure forms droplets due to breaking, and the droplets have a small size. The homogenization parameters, such as the pressure or temperature, modify the final characteristics of the nanoemulsions (Jin et al., 2016; Lee \& Norton, 2013). Galvão, Vicente, and Sobral (2018) designed nanoemulsions with pepper extracts using a high-speed homogenizer followed by a high-pressure homogenizer. Nanoemulsions were evaluated based on their environmental (centrifugal and thermal) and storage stabilities, and it was found that the nanoemulsions were stable during centrifugation and under most thermal stresses when stored at $4{ }^{\circ} \mathrm{C}$ and room temperature for more than 120 days.

\section{Microfluidizer homogenization}

Microfluidization is very similar to the highpressure homogenization method, and the terms are used interchangeably. The equipment has a narrow orifice through which the emulsions are pumped. The droplets undergo high shear to 
form nanoemulsions. Similar to high-pressure homogenization, microfluidization requires multiple recirculation so that the droplets will reach a desired final size (Gothsch et al., 2011; Gupta et al., 2016). Raviadaran, Chandran, Shin, and Manickam (2018) optimized a palm oil-based nanoemulsion to encapsulate curcumin using a microfluidizer and considered the microfluidizer pressure, the number of cycles and the concentration of surfactant (Tween 80) to obtain droplet sizes from $200 \mathrm{~nm}$ to $300 \mathrm{~nm}$.

\section{Ultrasonication}

Ultrasound technology relies on mechanical waves at a frequency above the threshold of the human ear $(>16 \mathrm{kHz})$. With this method, it is possible to obtain fine emulsions, which transform into smaller, more stable emulsions than those produced by other conventional techniques (Silva, Rosa, \& Meireles, 2015). It is one of the most effective methods for the preparation of nanoemulsions for research purposes in the food industry (Moghimi, Aliahmadi, McClements, \& Rafati, 2016; Sugumar, Ghosh, Mukherjee, \& Chandrasekaran, 2016). The dispersions produced by ultrasound are more stable, and the small droplets show an excellent particle size distribution (Silva et al., 2015). Because ultrasonication uses high-intensity waves to generate intense disturbing forces within mixtures of oil and water, it promotes a decrease in the droplet size (Ghosh, Mukherjee, \& Chandrasekaran, 2014; Moghimi et al., 2016; Tan et al., 2016). The use of ultrasound in the formation of nanoemulsions has shown promising results because there are no extra requirements for emulsion manufacturing (Nejadmansouri, Hosseini, Niakosari, Yousefi, \& Golmakani, 2016). Shao et al. (2018) prepared a new eugenol nanoemulsion using ultrasonication as an emulsification technique, and the droplets obtained had a regular spherical shape with a size of $80-100 \mathrm{~nm}$. In addition, the nanoemulsions showed high storage and thermal stabilities and presented excellent antioxidant capacity and antimicrobial activity, among others.

\section{Materials used in the development of nanoemulsions}

Nanoemulsion applications in food are becoming popular in the food industry to encapsulate components with potential biological activity, such as some fatty acids, liposoluble flavours, vitamins and others (Rao \& McClements, 2011). Emulsifiers help in the production of emulsions by adsorbing at the water-oil interface during homogenization to decrease the interfacial tension (Yang, Leser, Sher, \& McClements, 2013). The emulsifier must have certain characteristics: (1) it must rapidly reduce the interfacial tension at the newly formed water-oil interface; (2) it must be strongly bound to the interface once adsorbed; and (3) it must protect the droplets against destabilization. In many food process situations, the adsorption kinetics and interface stabilization processes are complicated because the emulsifiers have polydispersed sizes and are very different in their chemical compositions (Dickinson, 2009). The stability of electrostatically and sterically stabilized dispersions can be controlled by the charge of the electrical double layer and the thickness of the droplet surface layer formed by a non-ionic emulsifier (Capek, 2004). Emulsifiers and surfactants can be classified in various ways. One of the most common classifications is based on their application, i.e., emulsifiers, foaming agents, wetting agents and dispersants, among others. They can also be classified according to some physical characteristics, such as their affinity for water/oil or stability in hostile environments, and this is the classification most commonly used. According to the production source, surfactants can be classified as synthetic or natural. Moreover, it is possible to group them into four classes of primary surfactants: anionic, nonionic, cationic and amphoteric (Myers, 2005). The substitution of synthetic emulsifiers with natural emulsifiers is a growing tendency since many synthetic emulsifiers are not permitted for use in many countries or can only be used at low levels due to legislative, monetary, or sensorial problems (Rao \& McClements, 2011). Because of this situation, naturally occurring emulsifiers are a better choice for the development of nanoemulsions. Natural emulsifiers include proteins, polysaccharides and gums. Proteins act as 
emulsifiers because of their amphiphilic characteristics, which confer the ability to adsorb at the oil-water interface and decrease interfacial tension. Polysaccharides, on the other hand, provide stability to emulsions mainly by increasing the viscosity of the continuous phase (Silva et al., 2015).

Silva, Cerqueira, and Vicente (2012) listed the emulsifiers that have been used in the development of nanoemulsions. Non-ionic emulsifiers, such as polyethylene glycol castor oil, polyoxyethylene-660-12-hydroxystearate, polyoxyethylene 4-lauryl ether, sucrose fatty acid ester (L1695), Span 20, Span 80, Tween 20, Tween 80, and Tween 40, have been used. Some anionic emulsifiers, such as Alkanol-XC and sodium dodecyl sulfate, have been used. The amphiphilic emulsifiers that have been used include some proteins, such as gelatin, whey protein isolate (WPI), whey protein concentrate (WPC), and whey hydrolysed protein (WPH). Modified starch and pectin have been used as anionic emulsifiers.

\subsection{Use of nanoemulsions in foods}

Currently, nanoemulsions have been designed to contribute to food safety via antimicrobial activity and the improvement of the availability of bioactive compounds due to the controlled release of the emulsion (Ranjan, Dasgupta, Ramalingam, \& Kumar, 2017) There are bioactive compounds that are difficult to incorporate into foods. These are non-polar compounds with high melting points and low solubilities in water. The use of nanoemulsions is an excellent method used to incorporate these bioactive compounds into foods (Angel Robles-Garcia et al., 2016; Lu, Kelly, \& Miao, 2016; Oehlke et al., 2014). Bioactive compounds, such as polyphenols, come mainly from plants and fruits (Hernandez-Fuentes et al., 2015; Valdes et al., 2015). Polyphenols have antioxidant, antimicrobial and anti-inflammatory properties (Perumalla \& Hettiarachchy, 2011). Emulsion-based polyphenol encapsulation systems have been developed for obtaining food with novel properties (Pimentel-Gonzalez et al., 2015). Consumers seek to find natural conservators in foods to re- place synthetic conservators (Seow, Yeo, Chung, \& Yuk, 2014). Essential oils are natural conservators with characteristics such as high reactivity and hydrophobicity that make them difficult to add to industrialized foods. Nanoemulsions are a way to add essential oils and keep the organoleptic properties of the foods in which they are incorporated.

The nanoemulsion development with applications in the food area and on the edible coating of food is shown in Table 1. These dispersions are generally $\mathrm{O} / \mathrm{W}$ and have mainly been designed to increase the stability of the encapsulated compounds, as well as to evaluate the behaviour of the nanoemulsions after exposure to gastric simulations. The work developed by Sari et al. (2015) incorporated curcumin in the oil drops of medium chain triglycerides using whey protein concentrate- 70 and Tween-80 as emulsifiers to observe the in vitro release kinetics and found that the nanoemulsion was relatively resistant to digestion with pepsin, but with pancreatin, the compounds were released. The authors concluded that nanoencapsulation of highly unstable lipophilic compounds is an effective means to increase certain properties, such as bioavailability. Silva et al. (2018), who also incorporated curcumin in a multilayer nanoemulsion using layers of alginate and chitosan, performed another study that observed bioavailability. These authors simulated in vitro digestion conditions and found that this type of nanoemulsion improved control over the speed and degree of digestibility when compared to the level of control observed with uncoated nanoemulsions. These results showed in vitro digestion is an alternative method that can be used with functional foods to achieve an increase in satiety by delaying the digestion of lipids. Some other researchers developed nanoemulsions to observe their stability for incorporation into a food matrix, as is the case in the work performed by Golfomitsou, Mitsou, Xenakis, and Papadimitriou (2018), where a nanoemulsion was used as a vehicle for the enrichment of milk emulsions with vitamin D3 in. The stability was examined for several weeks, and it was found that the encapsulation of vitamin D3 was directly related to the size of the nanoemulsion, indicating that the encapsulation of this type of biocomposite was viable. 
Use of nanoemulsions in food $\mid 111$

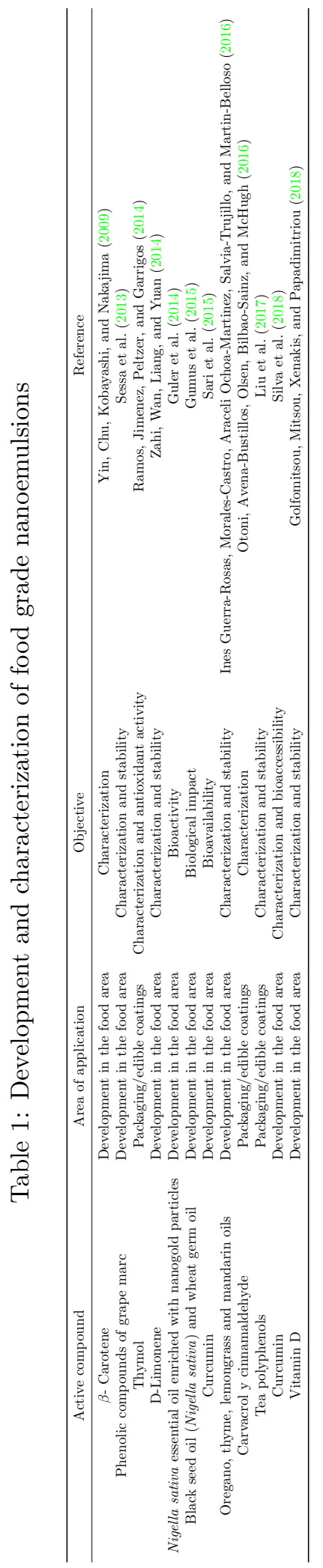

IJFS | October 2019 | Volume 8 | pages 105-124 
112 Cenobio-Galindo et al.

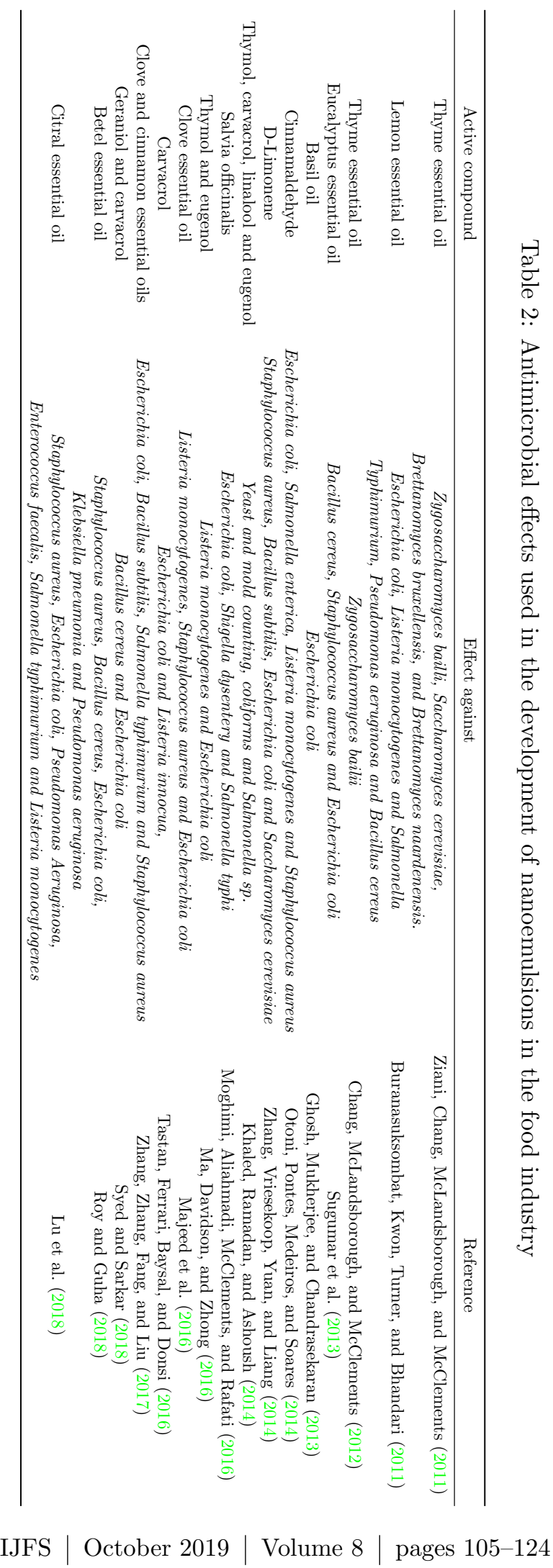


Table 2 shows the antimicrobial effect of nanoemulsions with bioactive compounds, which mainly contain essential oils or their derivatives. For example, the work performed by Buranasuksombat, Kwon, Turner, and Bhandari (2011), in which the authors developed a nanoemulsion containing lemon myrtle oil and compared it to a nanoemulsion of soybean oil that supposedly did not exhibit antimicrobial activity, confirmed antimicrobial action against Salmonella typhimurium, Escherichia coli 0157: H7, Pseudomonas aeruginosa, Bacillus cereus and Listeria monocytogenes by all emulsions. It was found that all of the emulsions with essential oils had the same level of antimicrobial effects against the five (5) bacteria, while all soybean oil emulsions had no antimicrobial effect. This antimicrobial activity was attributed to the encapsulated compounds. Another example of the antimicrobial use of nanoemulsions is in the work developed by Moghimi et al. (2016), where they encapsulated Salvia officinalis extract in a nanoemulsion using non-ionic surfactants (Tween 80, Span 80) and sonication. The antimicrobial activity of the nanoemulsions against foodborne bacteria (E. coli, Shigella dysentery and S. Typhimurium) was compared with that of the pure essential oil, and it was found that the antimicrobial effect of the nanoemulsion was four times greater than that of the oil. In addition, the results showed extensive damage of the bacterial cell membrane after treatment with the nanoemulsion. Zhang, Zhang, Fang, and Liu (2017) prepared nanoemulsions to encapsulate clove and cinnamon essential oils using Tween 80 and ethanol as a surfactant and cosurfactant, respectively. These nanoemulsions showed high antimicrobial activities against four tested microorganisms (E. coli, Bacillus subtilis, S. typhimurium and Staphylococcus aureus) when the nanoemulsions were at low concentrations, which shows that these compounds potentiate their effect when they are mixed and encapsulated in a stable system. The antimicrobial activity of emulsions based on geraniol and carvacrol against Bacillus cereus and Escherichia coli was evaluated, evaluated by Syed and Sarkar (2018) using ultrasonication, and it was demonstrated that this nanoemulsion prolonged the antibacterial efficacy of the combined emulsion of essential oils against both pathogens. The essen- tial oils contained in a nanoemulsion can pass through the cell membrane, affecting its functionality and providing a high antimicrobial effect (Donsi \& Ferrari, 2016).

At present, several studies have been carried out in which nanoemulsions serve to grant specific characteristics to complex food matrices. The high antimicrobial activity of nanoemulsions is the primordial effect that is sought when incorporating a nanoemulsion into food or coating food with a nanoemulsion, but the stability presenting when food is added should also be analysed. Table 3 shows several recent additions of nanoemulsions in foods. Several nanoemulsions have been tested in a few vegetal matrices to evaluate the effect after their application, e.g., in zucchini. Donsi, Cuomo, Marchese, and Ferrari (2014) observed the effect of the incorporation of a nanoemulsion based on carvacrol on the infusion rate. The results showed that emulsions of nanometric drop size smaller than the characteristic size exhibited a significantly improved effective diffusivity, which promoted a more effective antimicrobial action from carvacrol. ZambranoZaragoza et al. (2014) developed a nanoemulsion containing $\alpha$-tocopherol and applied it to freshly cut apples to evaluate their enzymatic behaviour and texture changes with respect to time. Results showed that the activity of the pectin methylesterase in the coated apples was lower in the submicron-size samples, helping to maintain the firmness of the apples coated with the nanoemulsion; the authors mention that the particle size of the emulsion drops is a determining parameter in controlling the texture and browning index in foods. In grapes, Oh et al. (2017) investigated the effects of the droplet size of a nanoemulsion containing lemongrass oil. This was carried out to determine the effectiveness of the emulsion coating in improving microbiological safety. Their results showed higher initial inhibition of Salmonella typhimurium; greater inhibition of the growth of total mesophilic aerobes, yeasts and molds; higher colour retention; and higher antioxidant activity, among others. The effect of nanoemulsions has also been determined in food of animal origins, such as chicken pâté (Moraes-Lovison et al., 2017) in which several quantities of oregano were incorporated into a nanoemulsion using the phase inversion tem- 
perature method to obtain stable nanoemulsions. The authors found that the incorporation of nanoemulsions in chicken meat did not modify the physicochemical characteristics of the meat product. Therefore, the results obtained indicated that nanoemulsions are suitable for their incorporation into food formulations to prevent and control microbial growth and extend food's useful life. In trout fillets, the use of nanoemulsions has been reported to extend their useful life. Shadman, Hosseini, Langroudi, and Shabani (2017) incorporated different concentrations of Zataria multiflora Boiss into nanoemulsions based on sunflower oil, incorporated the emulsion into fillets and evaluated the physicochemical and sensorial properties during storage. The results revealed that the nanoemulsion achieved a reduction in lipid oxidation, a characteristic attributed to the high contents of carvacrol and thymol. The nanoemulsion also contributed to increasing the acceptability of taste, odour and texture. Noori, Zeynali, and Almasi (2018) developed a sodium caseinate-based coating that contained a nanoemulsion that encapsulated ginger essential oil and applied the coating to chicken breast fillets to observe their behaviour. The coatings caused a decrease in the count of total aerobic psychrophiles and maintained the colour, achieving a better acceptance of the coated fillets and becoming an alternative to improve the shelf life of raw chicken meat.

Nanoemulsions have been applied in bakery products to observe their behaviour with respect to time. Otoni, de Moura, et al. (2014) produced nanoemulsions with the essential oils clove and oregano and incorporated them into methylcellulose films, improving the mechanical properties of the films. Slices of bread were coated with these films, and it was found that both oils managed to reduce mold and yeast counts. The authors mention that because of the particle size, bioavailability is improved, and thus, less preservative content can be used to obtain the same antimicrobial efficacy. It is evident that nanoemulsions help maintain some properties with respect to the shelf life of the product to which they were applied. Donsi and Ferrari (2016) classified four major macro-areas for the applications of nanoemulsions containing essential oils: a) Direct incorporation in liquid food, b) disinfection of the surface of the food with an antimicrobial dispersion, c) immersion into porous food matrices, and d) coverage with a biopolymer layer containing the nanoemulsion.

There are some cases of nanoemulsion use by world-class companies, such as Nestlé and Unilever. Nestlé has developed W/O nanoemulsions to make microwave defrosting easier for some foods by the incorporation of polysorbates and other compounds. Unilever produce a reduced-fat ice cream with the application of nanoemulsions (Silva et al., 2012). The German company AQUANOVA in its product line NovaSOL ${ }^{\circledR}$ has used nanoemulsions in the food industry and developed a varied product line focused on the protection and shelf life of various products, such as beverages and supplements, with essential oils, vitamins, and pigments, among others (AquaNova, 2016). The products based on nanoemulsions are very attractive because they are translucent in appearance and can increase the bioavailability of the bioactive component they possess. Preferably, nanotechnology should be simple to use and inexpensive, and it should have easily perceived benefits that may be considered as a real alternative to established techniques. Therefore, the food industry should use nanoemulsions from legally acceptable and ecologically and economically feasible ingredients (Ranjan et al., 2017).

\section{Risks and regulations of the utilization of nanotechnology in food}

There are some reports from the media about the possible adverse health effects of nanotechnology, and this has resulted in increased negative perceptions about this field and the food industry. Although there are risks associated with some nanomaterials used in foods, they should not be considered as potential risks as natural nanomaterials have been consumed since the Neolithic era (Bouwmeester et al., 2009; Rogers, 2016; Szakal et al., 2014).

In general, each country should have an organization that is responsible for regulating and verifying the risks associated with nanotechnology. The legislation available for the European Union 


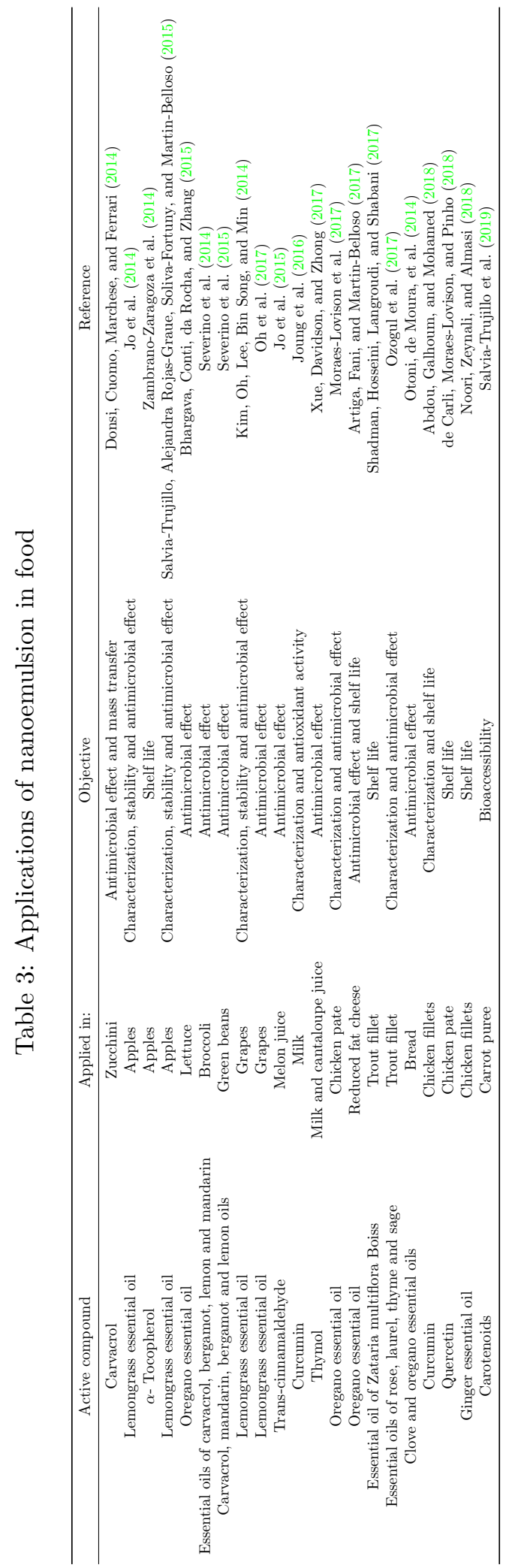

IJFS | October 2019 | Volume 8 | pages 105-124 
116 | Cenobio-Galindo et al.

can be consulted online at http://EUR-LEX. europa.eu/. In the United States, food additives are always subject to authorization by the Food and Drug Administration (FDA). The FDA has published some papers that approach the problems of nanotechnology, for example: "Considering Whether an FDA-Regulated Product Involves the Application of Nanotechnology" (U.S. Food and Drug Administration, 2014). In Canada, nanotechnology issues are reviewed by the Canadian Food Inspection Agency (CFIA); in Switzerland, by the Swiss Federal Office of Public Health (FOPH); in Japan, by the Ministry of Health, Labour and Welfare; and in China, by the Ministry of Health. Most countries continue to rely on existing legislation about nanomaterials, although a significant challenge exists between nanotechnology legislation and industrial application (Amenta et al., 2015). Improvement in the regulatory system is crucial to avoid consumer disinformation in relation to applied nanotechnology in food. Although the relevant legislation is still being developed, further action can be taken to obtain consumer acceptance in foods containing nanotechnology-based materials. This includes ensuring the use of food-grade ingredients to produce nanosystems (Singh, 2016). It is inevitable that human exposure to nanomaterials will increase in various ways, whether intentional or not. Nanomaterials, which serve as food additives (including nanoemulsions), come into direct contact with humans, resulting in higher levels of exposure depending on their addition to food. Thus, it is important to consider the risks of nanoemulsions in biochemical (solubility, metabolism/excretion) and toxicity profiles (Amenta et al., 2015; Landsiedel et al., 2012). For the evaluation of nanotoxicity, several criteria can be considered, such as exposure assessment, nanoparticle toxicology, biological fate, transport, persistence and transformation of nanoparticles, among others (Chau, Wu, \& Yen, 2007; Dreher, 2004). Therefore, the use of nanoemulsions with the incorporation of bioactive compounds in food should significantly attract the attention of the public and govern- mental sectors (Jovanovic, 2015).

\section{Conclusion}

The use of nanoemulsions, mainly as effective encapsulation systems, has received great interest from the food industry due to their advantages, including small droplet size, transparency and high stability. The food industry seeks to implement these nanosystems of encapsulation for the addition of compounds with biological activity, e.g., functional lipophilic substances.

Nanoemulsions have been used mainly in the development of some foods and beverages to enrich the bioavailability of certain compounds and to contribute to the stability of the foods that contain them. An interesting challenge involves the development of nanoemulsions that are compatible with the product in which they will be incorporated; therefore, there must be adequate knowledge about the formulation and functionality of the product. In addition, the application of nanoemulsions in food systems presents challenges, e.g., reducing production costs.

Consumer acceptance should be achieved based on research showing that nanoemulsions do not cause toxicity and that they are not toxic and do not accumulate in the human body. In addition, effective legislation for nanotechnology in food safety must be established. The use of nanotechnology in the food sector is a field of study in development that could improve food systems that provide functionality and improve aspects related to health.

\section{References}

Abdou, E. S., Galhoum, G. F., \& Mohamed, E. N. (2018). Curcumin loaded nanoemulsions/pectin coatings for refrigerated chicken fillets. Food Hydrocolloids, 83, 445-453. doi:10.1016/j.foodhyd.2018.05. 026

Acosta, E. (2009). Bioavailability of nanoparticles in nutrient and nutraceutical delivery. Current Opinion in Colloid $\&$ Interface Science, 14(1), 3-15. doi:10.1016/j. cocis.2008.01.002 
Ahmed, K., Li, Y., McClements, D. J., \& Xiao, H. (2012). Nanoemulsion- and emulsionbased delivery systems for curcumin: Encapsulation and release properties. Food Chemistry, 132(2), 799-807. doi:10.1016/j. foodchem.2011.11.039

Amenta, V., Aschberger, K., Arena, M., Bouwmeester, H., Moniz, F. B., Brandhoff, P., ... Peters, R. J. (2015). Regulatory aspects of nanotechnology in the agri/feed/food sector in eu and non-eu countries. Regulatory Toxicology and Pharmacology, 73(1), 463-476. doi:10.1016/j. yrtph.2015.06.016

Angel Robles-Garcia, M., Rodriguez-Felix, F., Marquez-Rios, E., Antonio Aguilar, J., Barrera-Rodriguez, A., Aguilar, J., ... Lizette Del-Toro-Sanchez, C. (2016). Applications of nanotechnology in the agriculture, food, and pharmaceuticals. Journal of Nanoscience and Nanotechnology, 16(8), 8188-8207. doi:10.1166/jnn.2016.12925

Anton, N., Gayet, P., Benoit, J.-P., \& Saulnier, P. (2007). Nano-emulsions and nanocapsules by the pit method: An investigation on the role of the temperature cycling on the emulsion phase inversion. International Journal of Pharmaceutics, 344 (1-2), 44-52. Conference on New Trends in Drug Delivery Systems, Paris, FRANCE, DEC 04, 2006. doi:10.1016/j.ijphann.2007.04.027

Anton, N., \& Vandamme, T. F. (2009). The universality of low-energy nano-emulsification. International Journal of Pharmaceutics, 377 (1-2), 142-147. doi:10.1016/j.ijpharm. 2009.05 .014

AquaNova. (2016). Crystal clear solutions. Overview, Accessed: 13 June 2018. Retrieved from https: / / www . aquanova . de / media / public / Product \% 20Folder / NovaSOL_overview.pdf

Artiga, M., Fani, A., \& Martin-Belloso, O. (2017). Improving the shelf life of low-fat cut cheese using nanoemulsion-based edible coatings containing oregano essential oil and mandarin fiber. Food Control, 76, 1-12. doi:10.1016/j.foodcont.2017.01.001

Bhargava, K., Conti, D. S., da Rocha, S. R. P., \& Zhang, Y. (2015). Application of an oregano oil nanoemulsion to the control of foodborne bacteria on fresh lettuce. Food Microbiology, 47, 69-73. doi:10.1016/j.fm. 2014.11.007

Bouwmeester, H., Dekkers, S., Noordam, M. Y., Hagens, W. I., Bulder, A. S., De Heer, C., ... Sips, A. J. A. M. (2009). Review of health safety aspects of nanotechnologies in food production. Regulatory toxicology and pharmacology, 53(1), 52-62.

Buranasuksombat, U., Kwon, Y. J., Turner, M., \& Bhandari, B. (2011). Influence of emulsion droplet size on antimicrobial properties. Food Science and Biotechnology, 20(3), 793-800. doi:10.1007/s10068-0110110-X

Capek, I. (2004). Degradation of kineticallystable o/w emulsions. Advances in Colloid and Interface Science, 107(2-3), 125-155. doi:10.1016/S0001-8686(03)00115-5

Chang, Y., McLandsborough, L., \& McClements, D. J. (2012). Physical properties and antimicrobial efficacy of thyme oil nanoemulsions: Influence of ripening inhibitors. Journal of Agricultural and Food Chemistry, 60(48), 12056-12063. doi:10.1021/ jf304045a

Chau, C.-F., Wu, S.-H., \& Yen, G.-C. (2007). The development of regulations for food nanotechnology. Trends in Food Science \& Technology, 18(5), 269-280. doi:10.1016/j. tifs.2007.01.007

Choi, A.-J., Kim, C.-J., Cho, Y.-J., Hwang, J.-K., \& Kim, C.-T. (2011). Characterization of capsaicin-loaded nanoemulsions stabilized with alginate and chitosan by selfassembly. Food and Bioprocess Technology, 4 (6), 1119-1126. doi:10.1007/s11947-0110568-9

Chuesiang, P., Siripatrawan, U., Sanguandeekul, R., McLandsborough, L., \& McClements, D. J. (2018). Optimization of cinnamon oil nanoemulsions using phase inversion temperature method: Impact of oil phase composition and surfactant concentration. Journal of Colloid and Interface Science, 514, 208-216. doi:10.1016/j.jcis.2017.11. 084

de Carli, C., Moraes-Lovison, M., \& Pinho, S. (2018). Production, physicochemical stability of quercetin-loaded nanoemulsions 
and evaluation of antioxidant activity in spreadable chicken pâtés. LWT-Food Science and Technology, 98. doi:10.1016/j. lwt.2018.08.037

Dickinson, E. (2009). Hydrocolloids as emulsifiers and emulsion stabilizers. Food $\mathrm{Hy}$ drocolloids, 23(6, SI), 1473-1482. 9th International Hydrocolloids Conference, Singapore, SINGAPORE, JUN 15-19, 2008. doi:10.1016/j.foodhyd.2008.08.005

Donsi, F., Cuomo, A., Marchese, E., \& Ferrari, G. (2014). Infusion of essential oils for food stabilization: Unraveling the role of nanoemulsion-based delivery systems on mass transfer and antimicrobial activity. Innovative Food Science 8 Emerging Technologies, 22, 212-220. doi:10.1016/j.ifset. 2014.01.008

Donsi, F., \& Ferrari, G. (2016). Essential oil nanoemulsions as antimicrobial agents in food. Journal of Biotechnology, 233, 106120. doi:10.1016/j.jbiotec.2016.07.005

Dreher, K. L. (2004). Health and environmental impact of nanotechnology: Toxicological assessment of manufactured nanoparticles. Toxicological Sciences, 7r(1), 3-5. doi:10. 1093/toxsci/kfh041

Duncan, T. V. (2011). Applications of nanotechnology in food packaging and food safety: Barrier materials, antimicrobials and sensors. Journal of Colloid and Interface Science, 363(1), 1-24. doi:10.1016/j.jcis.2011. 07.017

Galvão, K., Vicente, A., \& Sobral, P. (2018). Development, characterization, and stability of $\mathrm{o} / \mathrm{w}$ pepper nanoemulsions produced by high-pressure homogenization. Food and bioprocess technology, 11(2), 355-367.

Gharibzahedi, S. M. T., Mousavi, S. M., Hamedi, M., \& Ghasemlou, M. (2012). Response surface modeling for optimization of formulation variables and physical stability assessment of walnut oil-in-water beverage emulsions. Food Hydrocolloids, 26 (1), 293301. doi:10.1016/j.foodhyd.2011.06.006

Ghosh, V., Mukherjee, A., \& Chandrasekaran, N. (2013). Ultrasonic emulsification of foodgrade nanoemulsion formulation and evaluation of its bactericidal activity. Ultrason- ics Sonochemistry, 20(1), 338-344. doi:10. 1016/j.ultsonch.2012.08.010

Ghosh, V., Mukherjee, A., \& Chandrasekaran, N. (2014). Eugenol-loaded antimicrobial nanoemulsion preserves fruit juice against, microbial spoilage. Colloids and Surfaces B-biointerfaces, 114, 392-397. doi:10.1016/ j.colsurfb.2013.10.034

Golfomitsou, I., Mitsou, E., Xenakis, A., \& Papadimitriou, V. (2018). Development of food grade $\mathrm{o} / \mathrm{w}$ nanoemulsions as carriers of vitamin $\mathrm{d}$ for the fortification of emulsion based food matrices: A structural and activity study. Journal of Molecular Liquids, 268, 734-742. doi:10.1016/j. molliq. 2018.07.109

Gothsch, T., Finke, J. H., Beinert, S., Lesche, C., Schur, J., Buettgenbach, S., ... Kwade, A. (2011). Effect of microchannel geometry on high-pressure dispersion and emulsification. Chemical Engineering \& Technology, 34(3, SI), 335-343. doi:10.1002/ceat. 201000421

Graves, S., Meleson, K., Wilking, J., Lin, M. Y., \& Mason, T. G. (2005). Structure of concentrated nanoemulsions. Journal of Chemical Physics, 122(13). doi:10.1063/ 1.1874952

Guler, E., Barlas, F. B., Yavuz, M., Demir, B., Gumus, Z. P., Baspinar, Y., ... Timur, S. (2014). Bio-active nanoemulsions enriched with gold nanoparticle, marigold extracts and lipoic acid: In vitro investigations. Colloids and Surfaces B-biointerfaces, 121, 299-306. doi:10.1016/j. colsurfb. 2014.05. 026

Gumus, Z. P., Guler, E., Demir, B., Barlas, F. B., Yavuz, M., Colpankan, D., ... Timur, S. (2015). Herbal infusions of black seed and wheat germ oil: Their chemical profiles, in vitro bio-investigations and effective formulations as phyto-nanoemulsions. Colloids and Surfaces B-biointerfaces, 133, 73-80. doi:10.1016/j.colsurfb.2015.05.044

Gupta, A., Eral, H. B., Hatton, T. A., \& Doyle, P. S. (2016). Nanoemulsions: Formation, properties and applications. Soft Matter, 12(11), 2826-2841. doi:10.1039/ c5sm02958a 
Gutierrez, J. M., Gonzalez, C., Maestro, A., Sole, I., Pey, C. M., \& Nolla, J. (2008). Nanoemulsions: New applications and optimization of their preparation. Current Opinion in Colloid \& Interface Science, 13(4), 245251. doi:10.1016/j.cocis.2008.01.005

Hernandez-Fuentes, A. D., Trapala-Islas, A., Gallegos-Vasquez, C., Campos-Montiel, R. G., Pinedo-Espinoza, J. M., \& GuzmanMaldonado, S. H. (2015). Physicochemical variability and nutritional and functional characteristics of xoconostles (opuntia spp.) accessions from mexico. Fruits, 70(2), 109-116. doi:10 . 1051 / fruits / 2015002

Ines Guerra-Rosas, M., Morales-Castro, J., Araceli Ochoa-Martinez, L., SalviaTrujillo, L., \& Martin-Belloso, O. (2016). Long-term stability of food-grade nanoemulsions from high methoxyl pectin containing essential oils. Food Hydrocolloids, 52, 438-446.

Jafari, S. M., Assadpoor, E., He, Y., \& Bhandari, B. (2008). Re-coalescence of emulsion droplets during high-energy emulsification. Food Hydrocolloids, 22(7), 11911202. doi:10.1016/j.foodhyd.2007.09.006

Jin, W., Xu, W., Liang, H., Li, Y., Liu, S., \& Li, B. (2016). 1-nanoemulsions for food: Properties, production, characterization, and applications. In A. M. Grumezescu (Ed.), Emulsions (pp. 1-36). Nanotechnology in the Agri-Food Industry. doi:10.1016/B9780-12-804306-6.00001-5

Jo, W.-S., Song, H.-Y., Song, N.-B., Lee, J.-H., Min, S. C., \& Song, K. B. (2014). Quality and microbial safety of 'fuji' apples coated with carnauba-shellac wax containing lemongrass oil. LWT-Food Science and Technology, 55(2), 490-497. doi:10.1016/j. lwt.2013.10.034

Jo, Y.-J., Chun, J.-Y., Kwon, Y.-J., Min, S.-G., Hong, G.-P., \& Choi, M.-J. (2015). Physical and antimicrobial properties of transcinnamaldehyde nanoemulsions in water melon juice. LWT-Food Science and Technology, 60(1), 444-451. doi:10.1016/j.lwt. 2014.09.041

Joung, H. J., Choi, M.-J., Kim, J. T., Park, S., Jin Park, H., \& Hwa Shin, G. (2016).
Development of food-grade curcumin nanoemulsion and its potential application to food beverage system: Antioxidant property and in vitro digestion. Journal of food science, 81. doi:10.1111/1750-3841.13224

Jovanovic, B. (2015). Critical review of public health regulations of titanium dioxide, a human food additive. Integrated Environmental Assessment and Management, 11(1), 10-20. doi:10.1002/ieam.1571

Kabalnov, A. S., \& Shchukin, E. D. (1992). Ostwald ripening theory-applications to fluorocarbon emulsion stability. Advances in Colloid and Interface Science, 38, 69-97. doi:10.1016/0001-8686(92)80043-W

Khaled, F. M., Ramadan, A. K. M., \& Ashoush, I. A. (2014). Nanoencapsulation and nanoemulsion of bioactive compounds to enhance their antioxidant activity in food. International Journal of Food Science and Technology, 4(3), 1-22.

Kim, I.-H., Oh, Y. A., Lee, H., Bin Song, K., \& Min, S. C. (2014). Grape berry coatings of lemongrass oil-incorporating nanoemulsion. LWT-Food Science and Technology, 58(1), 1-10. doi:10.1016/j.lwt.2014.03.018

Landsiedel, R., Fabian, E., Ma-Hock, L., Wohlleben, W., Wiench, K., Oesch, F., \& van Ravenzwaay, B. (2012). Toxico/biokinetics of nanomaterials. Archives of Toxicology, 86(7, SI), 1021-1060. doi:10 . 1007/s00204-012-0858-7

Lee, L., \& Norton, I. T. (2013). Comparing droplet breakup for a high-pressure valve homogeniser and a microfluidizer for the potential production of food-grade nanoemulsions. Journal of Food Engineering, 114(2), 158-163. doi:10.1016/j.jfoodeng. 2012.08.009

Liu, F., Avena-Bustillos, R. J., Chiou, B.-S., Li, Y., Ma, Y., Williams, T. G., ... Zhong, F. (2017). Controlled-release of tea polyphenol from gelatin films incorporated with different ratios of free/nanoencapsulated tea polyphenols into fatty food simulants. Food Hydrocolloids, 62, 212-221. doi:10. 1016/j.foodhyd.2016.08.004

Lu, W., Kelly, A. L., \& Miao, S. (2016). Emulsion-based encapsulation and delivery systems for polyphenols. Trends in Food 
Science 8 Technology, 47, 1-9. doi:10. 1016/j.tifs.2015.10.015

Lu, W.-C., Huang, D.-W., Wang, C.-C., Yeh, C.-H., Tsai, J.-C., Huang, Y.-T., \& Li, P.-H. (2018). Preparation, characterization, and antimicrobial activity of nanoemulsions incorporating citral essential oil. Journal of Food and Drug Analysis, 26(1), 82-89.

Ma, Q., Davidson, P. M., \& Zhong, Q. (2016). Nanoemulsions of thymol and eugenol coemulsified by lauric arginate and lecithin. Food Chemistry, 206, 167-173. doi:10 . 1016/j.foodchem.2016.03.065

Magnuson, B. A., Jonaitis, T. S., \& Card, J. W. (2011). A brief review of the occurrence, use, and safety of food-related nanomaterials. Journal of Food Science, 76(6), R126R133. doi:10.1111/j.1750-3841.2011.02170. $\mathrm{x}$

Majeed, H., Liu, F., Hategekimana, J., Sharif, H. R., Qi, J., Ali, B., ... Zhong, F. (2016). Bactericidal action mechanism of negatively charged food grade clove oil nanoemulsions. Food Chemistry, 197(A), 7583. doi:10.1016/j.foodchem.2015.10.015

Mason, T. G., Wilking, J. N., Meleson, K., Chang, C. B., \& Graves, S. M. (2006). Nanoemulsions: Formation, structure, and physical properties. Journal of Physicscondensed Matter, 18(41), R635-R666. doi:10.1088/0953-8984/18/41/R01

McClements, D. J. (2015). Food emulsions: Principles, practices, and techniques, third edition. CRC Press. Retrieved from https: / / books . google . pt / books ? id = YOGYCgAAQBAJ

McClements, D. J. (2010). Emulsion design to improve the delivery of functional lipophilic components. In M. Doyle \& T. Klaenhammer (Eds.), Annual review of food science and technology, vol 1 (Vol. 1, pp. 241-269). Annual Review of Food Science and Technology. doi:10.1146/annurev.food.080708. 100722

McClements, D. J. (2012). Nanoemulsions versus microemulsions: Terminology, differences, and similarities. Soft matter, 8(6), 17191729.
McClements, D. J., \& Rao, J. (2011). Foodgrade nanoemulsions: Formulation, fabrication, properties, performance, biological fate, and potential toxicity. Critical Reviews in Food Science and Nutrition, 51 (4), 285-330. doi:10 . $1080 / 10408398$. 2011. 559558

Miller, C. A. (1988). Spontaneous emulsification produced by diffusion-a review. Colloids and Surfaces, 29(1), 89-102. doi:10.1016/ 0166-6622(88)80173-2

Moghimi, R., Aliahmadi, A., McClements, D. J., \& Rafati, H. (2016). Investigations of the effectiveness of nanoemulsions from sage oil as antibacterial agents on some food borne pathogens. LWT-Food Science and Technology, 71, 69-76. doi:10.1016/j.lwt.2016. 03.018

Moraes-Lovison, M., Marostegan, L. F. P., Peres, M. S., Menezes, I. F., Ghiraldi, M., Rodrigues, R. A. F., .. Pinho, S. C. (2017). Nanoemulsions encapsulating oregano essential oil: Production, stability, antibacterial activity and incorporation in chicken pate. LWT-Food Science and Technology, 77, 233-240. doi:10.1016/j.lwt.2016.11.061

Myers, D. (2005). Surfactant science and technology. Wiley. Retrieved from https://books. google.pt/books?id=gkRTe1z2Q6UC

Nejadmansouri, M., Hosseini, S. M. H., Niakosari, M., Yousefi, G. H., \& Golmakani, M. T. (2016). Physicochemical properties and storage stability of ultrasoundmediated wpi-stabilized fish oil nanoemulsions. Food Hydrocolloids, 61, 801-811. doi:10.1016/j.foodhyd.2016.07.011

Noori, S., Zeynali, F., \& Almasi, H. (2018). Antimicrobial and antioxidant efficiency of nanoemulsion-based edible coating containing ginger (zingiber officinale) essential oil and its effect on safety and quality attributes of chicken breast fillets. Food Control, 84, 312-320. doi:10.1016/j.foodcont. 2017.08.015

Oehlke, K., Adamiuk, M., Behsnilian, D., Graef, V., Mayer-Miebach, E., Walz, E., \& Greiner, R. (2014). Potential bioavailability enhancement of bioactive compounds using food-grade engineered nanomaterials: A review of the existing evidence. Food $\mathcal{E}$ 
Function, 5(7), 1341-1359. doi:10.1039/ c3fo60067j

Oh, Y. A., Oh, Y. J., Song, A. Y., Won, J. S., Song, K. B., \& Min, S. C. (2017). Comparison of effectiveness of edible coatings using emulsions containing lemongrass oil of different size droplets on grape berry safety and preservation. LWT-Food Science and Technology, 75, 742-750. doi:10.1016/j.lwt. 2016.10.033

Otoni, C. G., Avena-Bustillos, R. J., Olsen, C. W., Bilbao-Sainz, C., \& McHugh, T. H. (2016). Mechanical and water barrier properties of isolated soy protein composite edible films as affected by carvacrol and cinnamaldehyde micro and nanoemulsions. Food Hydrocolloids, 57, 72-79. doi:10.1016/ j.foodhyd.2016.01.012

Otoni, C. G., de Moura, M. R., Aouada, F. A., Camilloto, G. P., Cruz, R. S., Lorevice, M. V., ... Mattoso, L. H. C. (2014). Antimicrobial and physicalmechanical properties of pectin/papaya puree/cinnamaldehyde nanoemulsion edible composite films. Food Hydrocolloids, 41, 188-194.

Otoni, C. G., Pontes, S. F. O., Medeiros, E. A. A., \& Soares, N. d. F. F. (2014). Edible films from methylcellulose and nanoemulsions of clove bud (syzygium aromaticum) and oregano (origanum vulgare) essential oils as shelf life extenders for sliced bread. Journal of Agricultural and Food Chemistry, 62(22), 5214-5219.

Ozogul, Y., Yuvka, I., Ucar, Y., Durmus, M., Kosker, A. R., Oz, M., \& Ozogul, F. (2017). Evaluation of effects of nanoemulsion based on herb essential oils (rosemary, laurel, thyme and sage) on sensory, chemical and microbiological quality of rainbow trout (oncorhynchus mykiss) fillets during ice storage. LWT-Food Science and Technology, 75, 677-684. doi:10.1016/j. lwt . 2016.10.009

Pagan, E., Berdejo, D., Espina, L., GarciaGonzalo, D., \& Pagan, R. (2018). Antimicrobial activity of suspensions and nanoemulsions of citral in combination with heat or pulsed electric fields. Letters in Ap- plied Microbiology, 66(1), 63-70. doi:10. 1111/lam.12815

Perumalla, A. V. S., \& Hettiarachchy, N. S. (2011). Green tea and grape seed extractspotential applications in food safety and quality. Food Research International, 44(4), 827-839. doi:10 . 1016 / j . foodres . 2011.01 .022

Pimentel-Gonzalez, D. J., Aguilar-Garcia, M. E., Aguirre-Alvarez, G., Salcedo-Hernandez, R., Guevara-Arauza, J. C., \& CamposMontiel, R. G. (2015). The process and maturation stability of chihuahua cheese with antioxidants in multiple emulsions. Journal of Food Processing and Preservation, 39(6), 1027-1035. doi:10.1111/jfpp. 12317

Pradhan, N., Singh, S., Ojha, N., Shrivastava, A., Barla, A., Rai, V., \& Bose, S. (2015). Facets of nanotechnology as seen in food processing, packaging, and preservation industry. Biomed Research International. doi:10.1155/2015/365672

Qian, C., \& McClements, D. J. (2011). Formation of nanoemulsions stabilized by model food-grade emulsifiers using high-pressure homogenization: Factors affecting particle size. Food Hydrocolloids, 25 (5), 1000-1008. doi:10.1016/j.foodhyd.2010.09.017

Raj, A. A. S., Ragavi, J., Rubila, S., Tirouthchelvamae, D., \& Ranganathan, T. V. (2013). Recent trends in nanotechnology applications in foods. IJERT, 2(10), 956-961.

Ramos, M., Jimenez, A., Peltzer, M., \& Garrigos, M. C. (2014). Development of novel nano-biocomposite antioxidant films based on poly (lactic acid) and thymol for active packaging. Food Chemistry, 162, 149-155. doi:10.1016/j.foodchem.2014.04.026

Ranjan, S., Dasgupta, N., Ramalingam, C., \& Kumar, A. (2017). Nanotechnology in nutraceuticals production to consumption. In S. Sen \& Y. Pathak (Eds.), (Chap. Nanoemulsions in Food Science and Nutrition, pp. 147-152). doi:10.1201/9781315370859

Rao, J., \& McClements, D. J. (2011). Food-grade microemulsions, nanoemulsions and emulsions: Fabrication from sucrose monopalmitate \& lemon oil. Food Hydrocolloids, 
25(6), 1413-1423. doi:10.1016/j.foodhyd. 2011.02.004

Raviadaran, R., Chandran, D., Shin, L. H., \& Manickam, S. (2018). Optimization of palm oil in water nano-emulsion with curcumin using microfluidizer and response surface methodology. LWT-Food Science and Technology, 96, 58-65. doi:10.1016/j.lwt.2018. 05.022

Roger, K., \& Cabane, B. (2012). Why are hydrophobic/water interfaces negatively charged? Angewandte Chemie (International ed. in English), 51, 5625-8. doi:10. 1002/anie.201108228

Rogers, M. A. (2016). Naturally occurring nanoparticles in food. Current Opinion in Food Science, 7, 14-19. doi:10.1016/j.cofs. 2015.08.005

Roy, A., \& Guha, P. (2018). Formulation and characterization of betel leaf (piper betle l.) essential oil based nanoemulsion and its in vitro antibacterial efficacy against selected food pathogens. Journal of Food Processing and Preservation, 42(6). doi:10.1111/jfpp. 13617

Salvia-Trujillo, L., Verkempinck, S. H. E., Zhang, X., Van Loey, A. M., Grauwet, T., \& Hendrickx, M. E. (2019). Comparative study on lipid digestion and carotenoid bioaccessibility of emulsions, nanoemulsions and vegetable-based in situ emulsions. Food Hydrocolloids, 87, 119-128. doi:10.1016 / j . foodhyd.2018.05.053

Salvia-Trujillo, L., Alejandra Rojas-Graue, M., Soliva-Fortuny, R., \& Martin-Belloso, O. (2015). Use of antimicrobial nanoemulsions as edible coatings: Impact on safety and quality attributes of fresh-cut fuji apples. Postharvest Biology and Technology, 105, 8-16. doi:10.1016/j. postharvbio.2015.03. 009

Sari, T. P., Mann, B., Kumar, R., Singh, R. R. B., Sharma, R., Bhardwaj, M., \& Athira, S. (2015). Preparation and characterization of nanoemulsion encapsulating curcumin. Food Hydrocolloids, 43, 540-546. doi:10 . 1016/j.foodhyd.2014.07.011

Seow, Y. X., Yeo, C. R., Chung, H. L., \& Yuk, H.-G. (2014). Plant essential oils as active antimicrobial agents. Critical Reviews in Food Science and Nutrition, 54(5), 625644. doi:10.1080/10408398.2011.599504

Sessa, M., Casazza, A. A., Perego, P., Tsao, R., Ferrari, G., \& Donsi, F. (2013). Exploitation of polyphenolic extracts from grape marc as natural antioxidants by encapsulation in lipid-based nanodelivery systems. Food and Bioprocess Technology, 6(10), 2609-2620. doi:10.1007/s11947-012-0911-9

Severino, R., Ferrari, G., Vu, K. D., Donsi, F., Salmieri, S., \& Lacroix, M. (2015). Antimicrobial effects of modified chitosan based coating containing nanoemulsion of essential oils, modified atmosphere packaging and gamma irradiation against escherichia coli o157:h7 and salmonella typhimurium on green beans. Food Control, 50, 215-222. doi:10.1016/j.foodcont.2014.08.029

Severino, R., Vu, K. D., Donsi, F., Salmieri, S., Ferrari, G., \& Lacroix, M. (2014). Antimicrobial effects of different combined nonthermal treatments against listeria monocytogenes in broccoli florets. Journal of Food Engineering, 124, 1-10. doi:10.1016/ j.jfoodeng.2013.09.026

Shadman, S., Hosseini, S. E., Langroudi, H. E., \& Shabani, S. (2017). Evaluation of the effect of a sunflower oil-based nanoemulsion with zataria multiflora boiss. essential oil on the physicochemical properties of rainbow trout (oncorhynchus mykiss) fillets during cold storage. LWT-Food Science and Technology, 79, 511-517. doi:10.1016/ j.lwt.2016.01.073

Shah, P., Bhalodia, D., \& Shelat, P. (2010). Nanoemulsion: A pharmaceutical review. Systematic Reviews in Pharmacy, 1. doi:10. 4103/0975-8453.59509

Shakeel, F., Ramadan, W., Faisal, M. S., Rizwan, M., Faiyazuddin, M., Mustafa, G., \& Shafiq, S. (2010). Transdermal and topical delivery of anti-inflammatory agents using nanoemulsion/microemulsion: An updated review. Current Nanoscience, 6(2), 184-198. doi:10.2174/157341310790945740

Shao, Y., Wu, C., Wu, T., Li, Y., Chen, S., Yuan, C., \& Hu, Y. (2018). Eugenol-chitosan nanoemulsions by ultrasound-mediated emulsification: Formulation, characterization and antimicrobial activity. Carbohydrate 
Polymers, 193, 144-152. doi:10.1016/j . carbpol.2018.03.101

Silva, E. K., Rosa, M. T. M. G., \& Meireles, M. A. A. (2015). Ultrasound-assisted formation of emulsions stabilized by biopolymers. Current Opinion in Food Science, 5, 50-59. doi:10.1016/j.cofs.2015.08.007

Silva, H. D., Poejo, J., Pinheiro, A. C., Donsi, F., Serra, A. T., Duarte, C. M. M., ... Vicente, A. A. (2018). Evaluating the behaviour of curcumin nanoemulsions and multilayer nanoemulsions during dynamic in vitro digestion. Journal of Functional Foods, 48, 605-613. doi:10.1016/j.jff.2018.08.002

Silva, H. D., Cerqueira, M. A., \& Vicente, A. A. (2012). Nanoemulsions for food applications: Development and characterization. Food and Bioprocess Technology, 5(3), 854867. doi:10.1007/s11947-011-0683-7

Singh, H. (2016). Nanotechnology applications in functional foods; opportunities and challenges. Preventive nutrition and food science, 21, 1-8. doi:10.3746/pnf.2016.21.1.1

Solans, C., Izquierdo, P., Nolla, J., Azemar, N., \& Garcia-Celma, M. J. (2005). Nanoemulsions. Current Opinion in Colloid \&6 Interface Science, 10(3), 102-110. doi:10. 1016/j.cocis.2005.06.004

Sonneville-Aubrun, O., Babayan, D., Bordeaux, D., Lindner, P., Rata, G., \& Cabane, B. (2009). Phase transition pathways for the production of $100 \mathrm{~nm}$ oil-in-water emulsions. Physical Chemistry Chemical Physics, 11(1), 101-110. doi:10 . 1039/ b813502a

Sugumar, S., Ghosh, V., Mukherjee, A., \& Chandrasekaran, N. (2016). Essential oil-based nanoemulsion formation by low- and highenergy methods and their application in food preservation against food spoilage microorganisms. doi:10 . 1016 / B978 - 0 - 12 416641-7.00009-2

Sugumar, S., Nirmala, J., Ghosh, V., Anjali, H., Mukherjee, A., \& Chandrasekaran, N. (2013). Bio-based nanoemulsion formulation, characterization and antibacterial activity against food-borne pathogens. Journal of Basic Microbiology, 53(8), 677-685. doi:10.1002/jobm.201200060
Surh, J., Decker, E. A., \& McClements, D. J. (2017). Utilisation of spontaneous emulsification to fabricate lutein-loaded nanoemulsion-based delivery systems: Factors influencing particle size and colour. International Journal of Food Science and Technology, 52(6), 1408-1416. doi:10.1111/ ijfs. 13395

Syed, I., \& Sarkar, P. (2018). Ultrasonicationassisted formation and characterization of geraniol and carvacrol-loaded emulsions for enhanced antimicrobial activity against food-borne pathogens. Chemical Papers, 72(10), 2659-2672. doi:10.1007/s11696018-0501-z

Szakal, C., Roberts, S. M., Westerhoff, P., Bartholomaeus, A., Buck, N., Illuminato, I., ... Rogers, M. (2014). Measurement of nanomaterials in foods: Integrative consideration of challenges and future prospects. ACS Nano, 8(4), 3128-3135. doi:10.1021/ $\mathrm{nn} 501108 \mathrm{~g}$

Tadros, T., Izquierdo, R., Esquena, J., \& Solans, C. (2004). Formation and stability of nanoemulsions. Advances in Colloid and Interface Science, 108, 303-318. 3rd World Congress on Emulsions, Lyon, FRANCE, SEP 24-27, 2002. doi:10.1016/j.cis.2003.10. 023

Tan, S. F., Masoumi, H. R. F., Karjiban, R. A., Stanslas, J., Kirby, B. P., Basri, M., \& Bin Basri, H. (2016). Ultrasonic emulsification of parenteral valproic acid-loaded nanoemulsion with response surface methodology and evaluation of its stability. Ultrasonics Sonochemistry, 29, 299-308. doi:10. 1016/j.ultsonch.2015.09.015

Tastan, O., Ferrari, G., Baysal, T., \& Donsi, F. (2016). Understanding the effect of formulation on functionality of modified chitosan films containing carvacrol nanoemulsions. Food Hydrocolloids, 61, 756-771. doi:10. 1016/j.foodhyd.2016.06.036

Taylor, P. (1998). Ostwald ripening in emulsions. Advances in Colloid and Interface Science, 75 (2), 107-163. doi:10.1016/S00018686(98)00035-9

U.S. Food and Drug Administration. (2014). Guidance for industry e considering whether an fda-regulated product in- 
volves the application of nanotechnology. Retrieved from http : / / www . fda . gov / regulatoryinformation / guidances / ucm257698.htm

Valdes, A., Mellinas, A. C., Ramos, M., Burgos, N., Jimenez, A., \& Garrigos, M. C. (2015). Use of herbs, spices and their bioactive compounds in active food packaging. $R S C$ Advances, 5 (50), 40324-40335. doi:10. $1039 / \mathrm{c} 4 \mathrm{ra17286h}$

Xue, J., Davidson, P. M., \& Zhong, Q. (2017). Inhibition of escherichia coli o157:h7 and listeria monocytognes growth in milk and cantaloupe juice by thymol nanoemulsions prepared with gelatin and lecithin. Food Control, 73(B), 1499-1506. doi:10.1016/j. foodcont.2016.11.015

Yang, Y., Leser, M. E., Sher, A. A., \& McClements, D. J. (2013). Formation and stability of emulsions using a natural small molecule surfactant: Quillaja saponin (qnaturale (r)). Food Hydrocolloids, 30(2), 589-596. doi:10.1016/j. foodhyd.2012.08. 008

Yin, L.-J., Chu, B.-S., Kobayashi, I., \& Nakajima, M. (2009). Performance of selected emulsifiers and their combinations in the preparation of beta-carotene nanodispersions. Food Hydrocolloids, 23(6), 16171622 .

Zahi, M. R., Wan, P., Liang, H., \& Yuan, Q. (2014). Formation and stability of d-limonene organogel-based nanoemulsion prepared by a high-pressure homogenizer. Journal of agricultural and food chemistry, 62(52), 12563-12569.

Zambrano-Zaragoza, M. L., Gutiérrez-Cortez, E., Del Real, A., González-Reza, R. M., Galindo-Pérez, M. J., \& QuintanarGuerrero, D. (2014). Fresh-cut red delicious apples coating using tocopherol/mucilage nanoemulsion: Effect of coating on polyphenol oxidase and pectin methylesterase activities. Food Research International, 62, 974-983.

Zhang, S., Zhang, M., Fang, Z., \& Liu, Y. (2017). Preparation and characterization of blended cloves/cinnamon essential oil nanoemulsions. LWT-Food Science and Technology, 75, 316-322.
Zhang, Z., Vriesekoop, F., Yuan, Q., \& Liang, H. (2014). Effects of nisin on the antimicrobial activity of d-limonene and its nanoemulsion. Food chemistry, 150, 307-312.

Ziani, K., Chang, Y., McLandsborough, L., \& McClements, D. J. (2011). Influence of surfactant charge on antimicrobial efficacy of surfactant-stabilized thyme oil nanoemulsions. Journal of agricultural and food chemistry, 59(11), 6247-6255. 